\title{
Which dimensions of food-related lifestyle are likely to be associated with obesity in Italy?
}

\author{
Anna Saba*, Elena Cupellaro and Marco Vassallo \\ Istituto Nazionale di Ricerca per gli Alimenti e la Nutrizione, Via Ardeatina 546, 00178 Rome, Italy
}

Submitted 8 February 2012: Final revision received 10 December 2012: Accepted 4 January 2013: First published online 8 February 2013

\begin{abstract}
Objective: To compare obese $v$. non-obese consumers in terms of their general food-related lifestyles and to explore possible food-related factors affecting obesity in Italy.

Design: The data were collected using a self-completion questionnaire. Data included sociodemographic information, measures of the Food-Related Lifestyle scale (FRL) and self-reported weight and height. A logistic regression model was fitted for the sample with obesity as the dependent variable and sociodemographic characteristics and FRL dimensions as the independent variables.

Setting: The survey was carried out in Italy between October and November 2010. Subjects: One thousand respondents were recruited with equal quotas for men $v$. women. The sample was representative of the Italian population in term of age groups and geographic areas. The participants were over 18 years of age and were solely or jointly responsible for the family's food shopping.

Results: Our analyses revealed that sociodemographic, economic and cultural variables affect the increasing rate of obesity in Italy. Obese respondents appeared to find more enjoyment from shopping and interest in cooking compared with non-obese ones. Moreover, they were more likely to find self-fulfilment in foods. However, obese respondents appeared to be less interested in the nutritional content of foods, suggesting their weak involvement in nutritional aspects when they eat. In fact, the obese respondents gave preference to snacks over meals.

Conclusions: The outcome of the study would suggest that in targeted interventions for public health purposes in order to address obesity, attention should be placed on the role that food plays in obese consumers' lives.
\end{abstract}

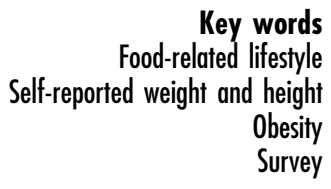

Although the mechanism of obesity development is not fully understood, it is confirmed that obesity is mainly due to an energy imbalance caused by excessive energy intake and physical inactivity over a considerable period ${ }^{(1,2)}$. There are multiple aetiologies for this imbalance and hence the rising prevalence of obesity cannot be addressed by a single aetiology. Genetic factors influence the susceptibility of a given child to an obesity-conducive environment. However, environmental factors, lifestyle preferences and cultural environment seem to play important roles in the rising prevalence of obesity ${ }^{(3,4)}$. Therefore a multidisciplinary analysis understanding the determinants of obesity is needed to prevent further expansion of the epidemic and to tackle its consequences.

Studies have shown an overall socio-economic gradient in obesity in modern industrialized societies ${ }^{(5,6)}$. Rates tend to decrease progressively with increasing socio-economic status, whether the latter is measured by income, education or occupation-based social class. In most Western societies, globalization of markets, economic development and marketing influence individual behaviour and also influence populations to differing extents depending on regional, national and local factors ${ }^{(7)}$. Thus the socio-economic inequalities in obesity are the result of a combination of multiple risk factors having a complex interrelationship between micro- and macro-environmental determinants ${ }^{(8)}$. There are several studies that point to income inequalities as a determinant of obesity in developed countries, because of lower dietary quality and leisure-time physical activities $^{(9,10)}$. A few studies have found that energy-dense foods are accessible to the consumer at a very low cost, and high-energy, low-cost foods are the more attractive option for low-income consumers ${ }^{(10,11)}$. Although a negative relationship between BMI and household income is a common result ${ }^{(12)}$, there are many confounding factors, especially race and gender, as this inverse relationship holds for women but not necessarily for men ${ }^{(13)}$. Part of the gender differences in socio-economic and ethnic inequalities might be explained also by differences in lifestyles, but hypotheses about possible explanations remain 
largely unexplored and therefore links between obesity and social status or inequality should be interpreted with caution $^{(5,7)}$. Furthermore, perceived social status and self-esteem may influence health behaviour, and obesity prevention may be less successful among lower-income groups than among those with higher incomes, increasing the health inequality ${ }^{(2)}$. Modern living happens under environmental conditions that facilitate unhealthy behaviours and choices. There is in fact evidence that in developed economies those countries with the longest average working hours have greater obesity levels, supporting the view that restricted leisure time increases the use of ready-prepared foods and fast-food outlets and reduces the time available for physical exercise ${ }^{(2,14)}$. A lot of economic research has examined the increased growth of obesity rates by analysing several factors that may contribute to the imbalance of energy consumption and expenditure ${ }^{(15-17)}$. For example, increased availability of restaurants and the food-away-fromhome industry, decreasing physical activity associated with work, urbanization and the increasing labour force participation rate of women have altered people's lifestyle and food choices ${ }^{(18)}$.

Attitudes towards fast foods and food-related factors, such as liking or disliking cooking and shopping, can contribute indirectly to weight gain and therefore are associated with the prevalence of obesity ${ }^{(19)}$. Thus a better understanding of the food-related attitudes of the segment of obese consumers could contribute to give a potential explanatory concept for obesity. The Food-Related Lifestyle scale (FRL) is a concept which has been used to measure people's attitudes to food-related factors ${ }^{(20,21)}$. FRL is a measurement instrument that collects consumer information on attitudes and behaviours concerning ways of shopping, purchasing motives, consumption situation, cooking methods and quality aspects. To the authors' knowledge, only one study has focused on the underlying association between FRL and obesity ${ }^{(22)}$. That research studied the association of FRL with obesity in five European countries (Belgium, Denmark, Germany, Greece and Poland) and identified specific FRL dimensions as potential predictors of obesity. It suggested that a stronger tendency to prefer snacks $v$. meals was a general phenomenon among the sample of obese consumers. Furthermore, the latter attached less importance to quality aspects relating to novelty, freshness, organic products and health, as compared with non-obese consumers, suggesting a lack of involvement with a holistic view of healthiness and foods.

Obesity rates are low in Italy (9\%) relative to most countries in the Organisation for Economic Co-operation and Development ${ }^{(23,24)}$, but the trend has been increasing in recent years. Focusing on this country, the objective of the present study was to compare obese $v$. non-obese consumers in terms of their general food-related lifestyles and to explore possible food-related factors affecting obesity in Italy.

\section{Methods}

\section{Participants and data collection}

The sample was representative of the Italian population in term of age groups and geographic areas. Telephone recruitment was conducted by a private research company using a computer-assisted telephone interviewing software. One thousand respondents were recruited with equal quotas for men $v$. women. People were included in the study if they were over 18 years of age and were solely or jointly responsible for the family's food shopping. The initial contact made by telephone was followed by a face-to-face contact to distribute the questionnaire. Subsequently, respondents were contacted by telephone to arrange an appointment to get back the completed questionnaire. The data were collected between October and November 2010 by means of a self-administered questionnaire.

The questionnaire included sociodemographic and anthropometric (self-reported height and weight) characteristics and the FRL question items. The FRL was used to measure the food-related lifestyles of Italian consumers. That instrument was used here as a tool to measure how people link food to the attainment of life values and to compare these between the groups of obese consumers $v$. non-obese consumers. The FRL instrument consists of sixty-nine item statements with seven-point interval scales ranging from 'totally disagree' to 'totally agree'. It measures twenty-three lifestyle dimensions covering the identification, preparation and actual intake of food products. The twentythree dimensions describe the five domains of Ways of Shopping, Quality Aspects, Cooking Methods, Consumption Situations and Purchasing Motives.

\section{Data analysis}

Sociodemographic variables were compared between the obese and non-obese consumer groups by using Pearson's $\chi^{2}$ test. Comparison of FRL score means between the obese and non-obese consumer groups was performed with the one-way ANOVA test.

Cronbach's $\alpha$ test was carried out to assess the internal reliability of the FRL dimensions and confirmatory factor analysis (CFA) was performed to assess the validity of measurement models (data not shown, but can be obtained from the first author). Values of Cronbach's $\alpha$ were found to be fairly satisfactory (ranging from 0.54 to $0 \cdot 82$ ) for most of the twenty-three FRL dimensions, whereas they were low for a few FRL dimensions indicating a low internal consistency. The CFA goodness-of-fit indices* were quite good for all domains according to the cut-off criteria. Most of the standardized factor loadings (i.e. regression coefficients) were significantly and substantially

\footnotetext{
* The fit of the general models was assessed by: (i) the $\chi^{2}$ statistic as a descriptive goodness-of-fit index ${ }^{(26)}$; (ii) the Comparative Fix index $(\mathrm{CFI})^{(27)}$; (iii) the root-mean-square error of approximation (RMSEA) ${ }^{(28)}$; and (iv) the Akaike information criterion (AIC) ${ }^{(29)}$
} 
different from zero (with values ranging from $0 \cdot 30$ to $0 \cdot 80$ ) and the factors' zero-order correlations were below $0 \cdot 85$, indicating acceptable convergent and discriminant validity, respectively ${ }^{(25)}$. However, some indicators* did not achieve a satisfactorily convergent validity due to non-significant values and/or being low in magnitude (i.e. under $0 \cdot 20$ ). Before removing these items from the analysis, we included them into each factorial design. Only those indicators which produced a significant improvement of the goodness-of-fit indices were kept for further analysis (data not shown, but can be obtained from the first author) and consequently conceptualized like new sub-dimensions of the original FRL domains. The preserved items were: (i) 'It is more important to choose food products for their nutritional value rather than for their taste', which belongs to the Quality Aspects domain and was re-labelled as 'Importance of nutritional value'; (ii) 'What we are going to have for supper is very often a last-minute decision', which belongs to the Cooking Methods domain and was re-labelled as 'Last-minute decision'; and (iii) 'I look for advertising in the newspaper for store specials and plan to take advantage of them when I go shopping', which belongs to the Ways of Shopping domain and was re-labelled as 'Looking for advertising'. Among these three indicators, only the 'Importance of nutritional value' was found to be significant in the logistic model and will be addressed in the text.

CFA were performed separately on each of five lifestyle domains (Ways of Shopping, Quality Aspects, Cooking Methods, Consumption Situations and Purchasing Motives) to achieve the convergent and discriminant validity among the underlying dimensions and then to validate the measurement models ${ }^{(25)}$. Multilevel logistic regression analyses were conducted. A dummy variable was created for obesity ( 1 = obese, $0=$ non-obese) and it was used as a categorical dependent variable in the logistic regression. The independent variables included in the logistic regression model were the FRL dimensions (scored as means), gender, age group, education, geographical area, health perception, number of children living in the household, single (yes, no), and frequency of eating 'fast food' and of eating 'take away'. A backward procedure based on the Wald $\dagger$ test was applied to retain in the model only

\footnotetext{
* 'Shopping for food does not interest me at all', 'I do not see any reason to shop in speciality food stores', 'Usually I do not decide what to buy until I am in the shop', 'I look for ads in the newspaper for store specials and plan to take advantage of them when I go shopping': these items belong to the Ways of Shopping domain. 'Well-known recipes are indeed the best', 'It is more important to choose food products for their nutritional value rather than for their taste': these items belong to the Quality Aspects domain. 'Nowadays the responsibility for shopping and cooking ought to lie just as much with the husband as with the wife', 'What we are going to have for supper is very often a last-minute decision': these items belong to the Cooking Methods domain. 'We often get together with friends to enjoy an easy-to-cook, casual dinner': this item belongs to the Consumption Situations domain.

$\uparrow$ The Wald statistic should be applied with caution in connection with logistic regression both for selecting predictors and for testing the
} statistical significance of the regression coefficients when the observed
Table 1 Sociodemographic characteristics of the sample: Italian men and women ( $n$ 1000) over 18 years of age, surveyed in October-November 2010

\begin{tabular}{lrr}
\hline & $n$ & $\%$ \\
\hline Gender & & \\
Male & 500 & $50 \cdot 0$ \\
Female & 500 & $50 \cdot 0$ \\
Age group & & \\
19-34 years & 267 & $26 \cdot 7$ \\
35-44 years & 180 & $18 \cdot 0$ \\
45-64 years & 313 & $31 \cdot 3$ \\
Z65 years & 240 & $24 \cdot 0$ \\
BMl† & 32 & $3 \cdot 2$ \\
Underweight & 510 & $51 \cdot 0$ \\
Normal weight & 344 & $34 \cdot 4$ \\
Overweight & 114 & $11 \cdot 4$ \\
Obesity & & $1 \cdot 1$ \\
Education & 11 & $11 \cdot 5$ \\
No education & 115 & $66 \cdot 6$ \\
Elementary & 666 & $17 \cdot 3$ \\
Secondary & 173 & $3 \cdot 5$ \\
Degree & 35 & \\
Post-degree & & \\
\hline
\end{tabular}

HUnderweight, BMI $<18.5 \mathrm{~kg} / \mathrm{m}^{2}$; normal weight, BMI $=18.5-24.9 \mathrm{~kg} / \mathrm{m}^{2}$; overweight, $\mathrm{BMI}=25 \cdot 0-29 \cdot 9 \mathrm{~kg} / \mathrm{m}^{2}$; obesity, $\mathrm{BMI} \geq 30 \cdot 0 \mathrm{~kg} / \mathrm{m}^{2}$.

the variables that had a significant effect on the dependent variable. Statistical analyses were performed using the statistical software packages SPSS Statistics 18.0 for Windows $^{\mathrm{TM}}$ and LISREL for Windows version $8 \cdot 80$.

\section{Results}

Table 1 shows the sociodemographic characteristics of the total sample. The majority of the respondents had higher education and were not living alone. The prevalence of obesity was $11 \cdot 1 \%(56 \cdot 1 \%$ of those obese were men and $43.9 \%$ were women), whereas $34.4 \%$ of respondents could be classified as overweight (58.6\% were men and $41.4 \%$ women). Half of the participants $(51 \cdot 0 \%)$ had a BMI within the normal range $(54 \cdot 8 \%$ were women), whereas $3 \cdot 2 \%$ were underweight (among whom $84 \cdot 4 \%$ were women). Respondents of the obese group had the highest percentage of older people $(P<0 \cdot 001)$ and they perceived their health more negatively compared with the non-obese group $(P<0 \cdot 001$; Table 2$)$.

Table 3 shows the mean scores on FRL dimensions of obese $v$. non-obese respondents in the sample. The obese group scored higher on freshness $(P<0.05)$ within the Quality Aspects domain, on 'Self-fulfilment in food' $(P<0 \cdot 05)$ among the Purchasing Motives and on

(footnote continued)

values of the sufficient statistic are on the boundary of the sample space $^{(30)}$ and in the presence of large coefficients where the standard error is inflated, in turn lowering the Wald statistic's value ${ }^{(31)}$. Nevertheless, these Wald statistic limitations seem to be effective only when the sample size is small and/or composed of sparse cells and/or when too many covariate data patterns are involved ${ }^{(32)}$, but this is not the case in the present study. 
Table 2 Distribution of BMI by gender, age group, education and perception of own health status: sample of Italian men and women ( $n$ 1000) over 18 years of age, surveyed in October-November 2010

\begin{tabular}{|c|c|c|c|c|c|c|c|}
\hline & & \multicolumn{4}{|c|}{ BMI } & \multirow[b]{3}{*}{$P$ value } & \multirow[b]{3}{*}{$\chi^{2}$ (Pearson } \\
\hline & \multirow[b]{2}{*}{$n$} & $\begin{array}{c}\text { Underweight } \\
(n \text { 32) }\end{array}$ & $\begin{array}{l}\text { Normal weight } \\
(n 510)\end{array}$ & $\begin{array}{l}\text { Overweight } \\
(n 344)\end{array}$ & $\begin{array}{l}\text { Obesity } \\
(n 114)\end{array}$ & & \\
\hline & & $\%$ & $\%$ & $\%$ & $\%$ & & \\
\hline \multicolumn{8}{|l|}{ Gender } \\
\hline Male & 500 & $1 \cdot 0$ & $46 \cdot 0$ & $40 \cdot 0$ & $13 \cdot 0$ & \multirow{2}{*}{$<0.001$} & \multirow{2}{*}{$31 \cdot 525$} \\
\hline Female & 500 & $5 \cdot 0$ & $56 \cdot 0$ & $29 \cdot 0$ & $10 \cdot 0$ & & \\
\hline \multicolumn{8}{|l|}{ Age group } \\
\hline 19-34 years & 267 & $7 \cdot 5$ & $62 \cdot 5$ & $25 \cdot 1$ & 4.9 & \multirow[t]{4}{*}{$<0.001$} & \multirow[t]{4}{*}{$82 \cdot 93$} \\
\hline $35-44$ years & 180 & $3 \cdot 3$ & $56 \cdot 7$ & $28 \cdot 9$ & $11 \cdot 1$ & & \\
\hline $45-64$ years & 313 & $1 \cdot 3$ & $50 \cdot 2$ & 33.9 & $14 \cdot 7$ & & \\
\hline$\geq 65$ years & 240 & 0.8 & $35 \cdot 0$ & $49 \cdot 6$ & $14 \cdot 6$ & & \\
\hline \multicolumn{8}{|l|}{ Education } \\
\hline No education & 11 & $0 \cdot 0$ & $27 \cdot 3$ & $54 \cdot 5$ & $18 \cdot 2$ & \multirow[t]{5}{*}{$<0.001$} & \multirow[t]{5}{*}{$51 \cdot 753$} \\
\hline Elementary & 115 & $1 \cdot 7$ & $27 \cdot 8$ & $53 \cdot 0$ & $17 \cdot \overline{4}$ & & \\
\hline Secondary & 666 & $2 \cdot 6$ & 53.0 & 33.5 & $11 \cdot 0$ & & \\
\hline Degree & 173 & $6 \cdot 9$ & $57 \cdot 8$ & $27 \cdot 7$ & $7 \cdot 5$ & & \\
\hline Post-degree & 35 & $2 \cdot 9$ & $62 \cdot 9$ & $17 \cdot 1$ & $17 \cdot 1$ & & \\
\hline \multicolumn{8}{|l|}{ Perceived health } \\
\hline Very bad & 9 & $11 \cdot 1$ & $33 \cdot 3$ & $33 \cdot 3$ & $22 \cdot 2$ & \multirow[t]{5}{*}{$<0.001$} & \multirow[t]{5}{*}{$43 \cdot 544$} \\
\hline $\mathrm{Bad}$ & 34 & $0 \cdot 0$ & $55 \cdot 9$ & $32 \cdot 4$ & $11 \cdot 8$ & & \\
\hline Fair & 291 & $3 \cdot 4$ & $40 \cdot 5$ & $38 \cdot 8$ & $17 \cdot 2$ & & \\
\hline Good & 436 & $3 \cdot 0$ & $49 \cdot 8$ & $37 \cdot 2$ & $10 \cdot 1$ & & \\
\hline Very good & 204 & $3 \cdot 9$ & $66 \cdot 2$ & $23 \cdot 5$ & $6 \cdot 4$ & & \\
\hline
\end{tabular}

fUnderweight, $\mathrm{BMI}<18 \cdot 5 \mathrm{~kg} / \mathrm{m}^{2} ;$ normal weight, $\mathrm{BMI}=18 \cdot 5-24 \cdot 9 \mathrm{~kg} / \mathrm{m}^{2} ;$ overweight, $\mathrm{BMI}=25 \cdot 0-29 \cdot 9 \mathrm{~kg} / \mathrm{m}^{2} ;$ obesity, $\mathrm{BMI} \geq 30 \cdot 0 \mathrm{~kg} / \mathrm{m}^{2}$.

'Enjoyment from shopping' $(P<0 \cdot 001)$ among the Ways of Shopping. Even though the differences between the two groups for other scores were not statistically significant, obese respondents attached higher levels of importance to 'Price criteria', which could reveal a higher level of awareness regarding the price when buying foods, and to 'Interest in cooking' which could indicate a higher involvement with food, at least regarding the food-related activities such as cooking. The obese respondents scored higher on dimensions in the Consumption Situation domain, particularly on 'Snacks $v$. meals', meaning that the obese respondents gave more preference to snacks over meals compared with the non-obese respondents. Finally, nonobese respondents scored higher on the 'Importance of nutritional value' dimension within the Quality Aspects domain of the FRL than obese respondents, showing their general involvement with the nutritional content of foods.

Table 4 shows the odds of being obese for those variables that were found to be statistically significant $(P<0 \cdot 05)$. The risk of being obese was higher among consumers who prefer to snack $(\mathrm{OR}=1 \cdot 17)$ than among those who eat only at mealtimes. Moreover, enjoyment from shopping increased the OR for obesity to $1 \cdot 24$, meaning that these consumers are $24 \%$ more likely to be obese. At the same time, negative associations were found between obesity and the importance of product information $(\mathrm{OR}=0 \cdot 80)$, the importance of nutritional value $(\mathrm{OR}=0 \cdot 78)$ and convenience $(\mathrm{OR}=0 \cdot 78)$, indicating that giving importance to these dimensions may decrease the risk of being obese. Females had $42 \%$
$(\mathrm{OR}=0.58)$ less probability to be obese than males. Absence of children in the household decreased the odds of becoming obese by $47 \%(\mathrm{OR}=0.53)$; that is, an increasing number of children increases the likelihood of being obese. Finally, the probability of being obese in those who perceived themselves to have good or bad health (both $\mathrm{OR}=0 \cdot 19$ ) was about $80 \%$ lower than in those who perceived their health to be very bad. That probability was almost $90 \%(\mathrm{OR}=0 \cdot 11)$ lower when respondents perceived their health to be very good.

\section{Discussion}

The present study found levels of overweight and obesity that were in line with previous studies carried out in Italy ${ }^{(24,33)}$ and confirmed that the prevalence of obesity among adults in Italy is relatively low compared with other countries ${ }^{(33,34)}$. However, as in those other studies, our information on weight and height was self-reported. Self-reported height and weight are considered feasible and useful measures in large-scale studies ${ }^{(35)}$, although overestimation of self-reported height and underestimation of self-reported weight have been documented in individuals of both genders ${ }^{(36)}$. This information is particularly crucial for researchers who evaluate the effects of BMI based on self-reported height and weight. However, the present study does not make any attempt to infer specific health risks that might be overestimated or underestimated by self-reporting of height and weight. BMI was used here in order to classify respondents for the purposes of better 
Table 3 Mean scores for Food-Related Lifestyle (FRL) dimensions and sub-dimensions according to obesity status: sample of Italian men and women ( $n$ 1000) over 18 years of age, surveyed in October-November 2010

\begin{tabular}{|c|c|c|c|c|}
\hline \multirow{2}{*}{$\begin{array}{l}\text { FRL domain/dimension or } \\
\text { sub-dimension }\end{array}$} & \multicolumn{2}{|c|}{ Non-obese } & \multicolumn{2}{|c|}{ Obese } \\
\hline & Mean & SD & Mean & SD \\
\hline \multicolumn{5}{|l|}{ Quality Aspects } \\
\hline Health & $5 \cdot 88$ & 1.02 & 5.92 & $0 \cdot 81$ \\
\hline Price/quality relation & $6 \cdot 04$ & 0.85 & $6 \cdot 08$ & $0 \cdot 80$ \\
\hline Novelty & $4 \cdot 71$ & $1 \cdot 52$ & $4 \cdot 66$ & 1.50 \\
\hline Organic products & $3 \cdot 98$ & 1.53 & 3.96 & 1.48 \\
\hline Taste & $6 \cdot 00$ & 0.98 & $6 \cdot 08$ & 0.92 \\
\hline Importance of nutritional valuet & $3 \cdot 28$ & $1 \cdot 60$ & $2 \cdot 86^{\star}$ & $1 \cdot 45$ \\
\hline Freshness & $6 \cdot 06$ & 0.96 & $6 \cdot 26^{*}$ & $0 \cdot 80$ \\
\hline \multicolumn{5}{|l|}{ Purchasing Motives } \\
\hline Self-fulfilment in food & $5 \cdot 04$ & $1 \cdot 20$ & $5 \cdot 30^{*}$ & $1 \cdot 34$ \\
\hline Security & $5 \cdot 13$ & 1.07 & $5 \cdot 21$ & 0.98 \\
\hline Social relationship & $5 \cdot 88$ & $0 \cdot 88$ & $5 \cdot 90$ & 0.93 \\
\hline \multicolumn{5}{|l|}{ Cooking Methods } \\
\hline Interest in cooking & $4 \cdot 43$ & $1 \cdot 36$ & $4 \cdot 73^{*}$ & 1.44 \\
\hline Looking for new ways & $4 \cdot 71$ & $1 \cdot 42$ & $4 \cdot 74$ & 1.47 \\
\hline Convenience & $3 \cdot 40$ & $1 \cdot 42$ & $3 \cdot 27$ & 1.48 \\
\hline Whole family & $4 \cdot 67$ & $1 \cdot 41$ & $4 \cdot 59$ & 1.55 \\
\hline Planning & $4 \cdot 06$ & $1 \cdot 49$ & $4 \cdot 23$ & 1.47 \\
\hline Last-minute decisiont & $3 \cdot 45$ & $1 \cdot 75$ & $3 \cdot 68$ & $1 \cdot 76$ \\
\hline Woman's task & $3 \cdot 65$ & $1 \cdot 72$ & $3 \cdot 71$ & 1.58 \\
\hline \multicolumn{5}{|l|}{ Ways of Shopping } \\
\hline Importance of product information & $5 \cdot 12$ & $1 \cdot 22$ & $5 \cdot 07$ & $1 \cdot 17$ \\
\hline Attitudes to advertising & $4 \cdot 06$ & $1 \cdot 34$ & $4 \cdot 07$ & $1 \cdot 28$ \\
\hline Enjoyment from shopping & $4 \cdot 65$ & $1 \cdot 50$ & $5 \cdot 14^{\star \star \star}$ & 1.43 \\
\hline Speciality shops & $4 \cdot 43$ & 1.46 & $4 \cdot 54$ & $1 \cdot 37$ \\
\hline Price criteria & $5 \cdot 57$ & $1 \cdot 28$ & $5 \cdot 85^{\star}$ & $1 \cdot 11$ \\
\hline Looking for advertising $\dagger$ & $3 \cdot 07$ & 1.93 & $3 \cdot 23$ & 1.91 \\
\hline Shopping list & $5 \cdot 34$ & $1 \cdot 55$ & $5 \cdot 50$ & $1 \cdot 56$ \\
\hline \multicolumn{5}{|l|}{ Consumption Situations } \\
\hline Snacks $v$. meals & $3 \cdot 14$ & $1 \cdot 40$ & 3.39 & 1.48 \\
\hline Social events & $3 \cdot 19$ & $1 \cdot 88$ & 3.29 & 1.94 \\
\hline
\end{tabular}

Mean scores were significantly different from those of non-obese respondents (one-way ANOVA): ${ }^{\star} P<0.05,{ }^{\star \star \star} P<0.001$.

tSub-dimensions.

understanding their food-related lifestyle as a potential explanatory concept for obesity.

Our analyses revealed that sociodemographic, economic and cultural variables affect the increasing rate of obesity in Italy. In agreement with previous economic studies found in the literature ${ }^{(33)}$, the present results highlighted that disadvantaged social categories, such as elderly people and those with a low level of education, are more susceptible to the problem of obesity. The increase of age tended to be accompanied by an increase in overweight and obesity. Among the young these data confirmed a favourable pattern, since obesity prevalence in Italians aged 19-34 years was about 5\%, which is lower than that of other countries ${ }^{(34)}$. Moreover, the results confirmed that males had a prevalence of obesity slightly higher than that of females ${ }^{(24,33)}$

The present study suggests that obesity may be associated with some FRL dimensions. Obese respondents appeared to find more enjoyment from shopping, interest in cooking and self-fulfilment in foods as compared with non-obese ones, confirming previous results ${ }^{(22)}$. This finding shows that obese consumers enjoy these aspects
Table 4 Odds of being obese according to associated Food-Related Lifestyle (FRL) dimensions/sub-dimensions and sociodemographic characteristics: sample of Italian men and women $(n$ 1000) over 18 years of age, surveyed in October-November 2010

\begin{tabular}{lcccr}
\hline & & \multicolumn{2}{c}{$95 \% \mathrm{Cl}$} \\
\cline { 3 - 4 } FRL/sociodemographic variable & OR & Lower & Upper & $P$ value \\
\hline Importance of product information & 0.80 & 0.66 & 0.97 & 0.025 \\
Enjoyment from shopping & 1.24 & 1.07 & 1.44 & 0.005 \\
Price criteria & 1.19 & 0.99 & 1.43 & 0.060 \\
Importance of nutritional valuet & 0.78 & 0.68 & 0.90 & 0.001 \\
Convenience & 0.78 & 0.66 & 0.93 & 0.005 \\
Whole family & 0.87 & 0.76 & 1.00 & 0.058 \\
Snacks $v$. meals & 1.17 & 1.00 & 1.37 & 0.047 \\
Social events & 1.13 & 0.99 & 1.27 & 0.052 \\
Gender (female) $\ddagger$ & 0.58 & 0.38 & 0.88 & 0.011 \\
Age & 1.19 & 0.97 & 1.44 & 0.089 \\
Children (no) $\ddagger$ & 0.53 & 0.34 & 0.80 & 0.003 \\
Perceived health (very bad) $\ddagger$ & & & & \\
$\quad$ Perceived health = bad & 0.19 & 0.04 & 0.90 & 0.036 \\
Perceived health = fair & 0.34 & 0.11 & 1.07 & 0.065 \\
Perceived health = good & 0.19 & 0.06 & 0.57 & 0.004 \\
Perceived health = very good & 0.11 & 0.03 & 0.37 & $<0.001$ \\
\hline
\end{tabular}

tSub-dimensions.

$\ddagger$ The $k$ values of the categorical variables are expressed in the model with $k-1$ dummy variables. When calculating the odds ratio, the value corresponding to cancellation of the dummy variable is regarded as the 'reference value'. For example, 'very bad' is the 'reference value' for the categorical variable 'perceived health'.

of foods, even though they do not seem to be involved with quality aspects of food as non-obese consumers are. Furthermore, obese respondents appeared to be less interested in the nutritional content of foods, suggesting their weak involvement in nutritional aspects when they eat. In fact, the obese respondents of our sample gave preference to snacks over meals, confirming results from another study ${ }^{(22)}$. The present study also suggests that giving importance to product information might decrease the risk of being obese. Therefore, the obese consumers of our sample would not choose what to eat on the basis of nutritional value and general information on the product. From a public health perspective, the fact that attitudes towards nutritional value and product information differ between obese and non-obese consumers raises concerns about the effectiveness of strategies targeting obese consumers to shift their consumption patterns. Moreover, the food choices of obese respondents related to snacking might be a cause for concern as they may facilitate increased energy intake, although the relationship between snacking and body weight was not found to be consistent across studies $^{(37,38)}$. However, some strategies specifically directed to the promotion of healthy snacking habits might achieve success in reducing energy intake of those who frequently eat snacks. Further, the findings suggest it is more probable that obese respondents perceive a very bad personal health, meaning that they might be conscious of the health risks associated with obesity ${ }^{(39)}$. Therefore, this would suggest that interventions focusing only on the health risks of obesity might provide minimal new information and induce few changes in eating behaviours. 
We are aware of some limits and weaknesses of our study concerning the type of observational design and the self-administered questionnaire as the method of data collection, respectively. The limits of an observational study here may be related to: (i) the precision ${ }^{(40)}$ of our sample, in that it is representative of the Italian population but not of obese Italian adults. Then, further research on representative samples of obese adults would be necessary to investigate their food-related lifestyles; (ii) the lack of a control group for understanding the cause of the obesity disease ${ }^{(41)}$. As regards the weaknesses of a selfadministered questionnaire, the main criticism usually relies on the correct and homogeneous interpretation of the same meaning of the observed scores on the constructs from all respondents ${ }^{(42)}$. However, the rigorous method of analysis through structural equation modelling in the form of CFA showed an acceptable convergent validity of the factor loadings, assuring that each factor has been commonly understood by the participants and adjusting for the remaining variance that they do not have in common (i.e. measurement error).

\section{Conclusion}

The outcome of the present study would suggest that in targeted interventions for public health purposes in order to address obesity, attention should be placed also on the role that food plays in obese consumers' lives. Then, further research should focus better on the relationship of food habits, obesity and lifestyles at country level and carry out cross-cultural comparisons in order to deepen different cultural contexts.

\section{Acknowledgements}

Sources of funding: The present study, conducted within the project PALINGENIO, was funded by the Italian Ministry of Agricultural, Food and Forestry Policies. The study was initiated and analysed by the investigators. Conflict of interest declaration: The authors declare that they have no competing interest. Authorship responsibilities: A.S. conceived and designed the study. E.C. and M.V. worked with the statistical models. E.C. ran the final analyses. All authors contributed to the interpretation of the data. A.S. drafted the initial and final manuscripts; M.V. and E.C. made critical revisions. All authors approved the final version of the manuscript.

\section{References}

1. Hyde R (2008) Europe battles with obesity. Lancet 371, 2160-2161.

2. Lobstein T \& Millstone E (2007) Context for the PorGrow study: Europe's obesity crisis. Obes Rev 8, Suppl. 2, 7-16.

3. Hill JO \& Peters JC (1998) Environmental contributions to the obesity epidemic. Science 280, 1371-1374.
4. Eckel RH \& Krauss RM (1998) American Heart Association call to action: obesity as a major risk factor for coronary heart disease. AHA Nutrition Committee. Circulation 97, 2099-2100.

5. Sassi F, Devaux M, Cecchini M et al. (2009) The Obesity Epidemic: Analysis of Past and Projected Future Trends in Selected OECD Countries. OECD Health Working Paper no. 45. Paris: OECD Publishing; available at http://dx.doi. org/10.1787/225215402672

6. Robertson A, Lobstein T \& Knai C (2007) Obesity and Socio-Economic Groups in Europe: Evidence Review and Implications for Action. Brussels: Report to the European Commission (Contract SANCO/2005/C4-NUTRITION-03).

7. James WPT, Rigby NJ, Leach RJ et al. (2006) Global strategies to prevent childhood obesity: forging a societal plan that works. International Association for the Study of Obesity/International Obesity Task Force. http://www. mcgill.ca/files/mwp/H_Chall06_glob_06_R.pdf (accessed January 2012).

8. Freedman DS, Khan LK, Serdula MK et al. (2002) Trends and correlates of class 3 obesity in the United States from 1990 through 2000. JAMA 288, 1758-17619.

9. Pickett KE, Kelly S, Brunner E et al. (2005) Wider income gaps, wider waistbands? An ecological study of obesity an income inequality. J Epidemiol Community Health 59, 670-674.

10. Drewnowski A \& Specter SE (2004) Poverty and obesity: the role of energy density and energy costs. Am J Clin Nutr 79, 6-16.

11. Drewnowski A \& Darmon N (2005) The economics of obesity: dietary energy density and energy cost. Am J Clin Nutr 82, 1 Suppl., 265S-273S.

12. Chou SY, Grossman AC \& Saffer H (2004) An economic analysis of adult obesity: results from the Behavioral Risk Factor Surveillance System. J Health Econ 23, 565-587.

13. Chang VW \& Lauderdale DS (2005) Income disparities in body mass index and obesity in the United States, 1971-2002. Arch Intern Med 165, 2122-2128.

14. Trogdon JG, Finkelstein EA, Hylands T et al. (2008) Indirect costs of obesity: a review of the current literature. Obes Rev 9, 489-500.

15. Loureiro M \& Nayga RM (2005) International dimensions of obesity and overweight related problems: an economics perspective. Am J Agric Econ 87, 1147-1153.

16. Lakdawalla D \& Philipson T (2007) Labor supply and weight. J Hum Resour 42, 85-116.

17. Cai Y, Alviola P, Nayga RM Jr et al. (2008) The effect of food away from home and food at home expenditures on obesity rates: a state level analysis. J Agric Appl Econ 40, $1-15$.

18. Morland K \& Evenson K (2009) Obesity prevalence and the local food environment. Health Place 15, 491-495.

19. Dave JM, An LC, Jeffery RW et al. (2009) Relationship of attitudes toward fast food and frequency of fast-food intake in adults. Obesity (Silver Spring) 17, 1164-1170.

20. Brunsø K \& Grunert KG (1995) Development and testing of a cross-culturally valid instrument: food-related life style. Adv Consum Res 22, 475-480.

21. Hoek AC, Luning PA, Stafleu A et al. (2004) Food-related lifestyle and health attitudes of Dutch vegetarians, nonvegetarian consumers of meat substitutes, and meat consumers. Appetite 42, 265-272.

22. Pérez-Cueto FJA, Verbeke W, de Barcellos MD et al. (2010) Food-related lifestyles and their association to obesity in five European countries. Appetite 54, 156-162.

23. Organisation for Economic Co-operation and Development (2010) Health At a Glance: Europe 2010. Paris: OECD Publishing; available at http://dx.doi.org/10.1787/health_ glance-2010-en 
24. Gallus S, Colombo P, Scarpino V et al. (2006) Overweight and obesity in Italian adults 2004, and an overview of trends since 1983. Eur J Clin Nutr 60, 1174-1179.

25. Kline B (2005) Principles and Practice of Structural Equation Modeling, 2nd ed. New York: The Guilford Press.

26. Jöreskog K \& Sörbom D (2002) LISREL 8: Structural Equation Modeling with the Simplis Command Language, 5th printing. Lincolnwood, IL: Scientific Software International Inc.

27. Bentler PM (1990) Comparative fit indexes in structural models. Psychol Bull 107, 238-246.

28. Nevitt J \& Hancock GR (2000) Improving the root mean square error of approximation for nonnormal conditions in structural equation modeling. J Exp Educ 68, 251-268.

29. Akaike H (1987) Factor analysis and AIC. Psychometrika 52, 317-332.

30. Vaeth M (1985) On the use of Wald's test in exponential families. Int Stat Rev 53, 199-214.

31. Menard S (1995) Applied Logistic Regression Analysis. Quantitative Applications in the Social Sciences Series no. 106. Thousand Oaks, CA: SAGE Publications.

32. Agresti A (1996) An Introduction to Categorical Data Analysis. Hoboken, NJ: John Wiley and Sons, Inc.

33. Banterle A \& Cavaliere A (2009) The social and economic determinants of obesity: an empirical study in Italy. Presented at 113th Seminar of the European Association of Agricultural Economists (EAAE), 'A resilient European food industry and food chain in a challenging world', Chania,
Crete, Greece, 3-6 September 2009; available at http:// ageconsearch.umn.edu/bitstream/90889/2/Cavaliere.pdf

34. Rennie KL \& Jebb SA (2005) Prevalence of obesity in Great Britain. Obes Rev 6, 11-12.

35. Goodman E \& Strauss RS (2003) Self-reported height and weight and the definition of obesity in epidemiological studies. I Adolesc Health 33, 140-141.

36. Danubio ME, Miranda G, Vinciguerra MG et al. (2008) Comparison of self-reported and measured height and weight: implications for obesity research among young adults. Econ Hum Biol 6, 181-190.

37. Bertéus Forslund H, Torgerson JS, Sjostrom L et al. (2005) Snacking frequency in relation to energy intake and food choices in obese men and women compared to a reference population. Int J Obes (Lond) 29, 711-719.

38. Phillips SM, Bandini JG, Naumova EN et al. (2004) Energydense snack food intake in adolescence: longitudinal relationship to weight and fatness. Obes Res 12, 461-472.

39. Finkelstein EA, Brown DS \& Evans WD (2008) Do obese persons comprehend their personal health risks? Am J Health Behav 32, 508-516.

40. Carlson MDA \& Morrison RS (2009) Study design, precision, and validity in observational studies. J Palliat Med 12, 77-82.

41. Grimes DA \& Schulz KF (2002) Descriptive studies: what they can and cannot do. Lancet 359, 145-149.

42. Spector PE (1994) Using self-reported questionnaires in OB research: a comment on the use of controversial method. J Organ Behav 15, 385-392. 